\title{
Review of The Slow Professor: Challenging the Culture of Speed in the Academy
}

The Slow Professor: Challenging the Culture of Speed in the Academy. Maggie Berg and Barbara K. Seeber, with a new Foreword by Stefan Collini. Toronto: University of Toronto Press, 2017, ISBN: 978-I-4875-2185-I.

I entered the academy having inherited a particular view of higher education from my mentors. They informed me about what I would face if I were lucky enough to land a teaching position. Not surprisingly, what they shared with me was an accurate foretelling of what I have experienced, including the exhausting Retention, Promotion, and Tenure (RPT) process, with its focus on research, teaching, and service - and ranked in that order!

It was after a quarter century of being a professor that I was fortunate enough to stumble upon The Slow Professor: Challenging the Culture of Speed in the Academy by Maggie Berg and Barbara K. Seeber, a book that expresses much of what I have found wanting in academic life.

The Slow Professor is an enlightening commentary on the contemporary life of the university professor. The authors begin with a foreword by Stefan Collini, a preface, and an introduction, followed by four chapters, a conclusion, and works cited (a whopping I5o titles).

Berg and Seeber have done well with Collini setting the stage in just five pages. Collini makes clear what awaits the reader of this timely book: an elucidation of "the existential condition" of today's professor. Building on Collini's claim that the book has "elements of a self-help manual," it is difficult not to read The Slow Professor as an "existential threat" to that very condition.

Collini tells us the existential condition of the professor has changed due to "the corporatization of higher education." What has emerged within the university is a managerialism that oversees the neoliberal model of economic production, one that seeks advantage in environments of intense competition. Administrators have increasingly redefined the academic life of professors in terms of productivity - requiring them to be as productive as possible in order to benefit from a limited (or even dwindling) pool of resources (viz., release time and money).

By emphasizing productivity as the measure of efficiency in converting inputs into useful outputs over time, time has become increasingly important. This in turn has made it even more urgent for professors to rise to the top of the institutional pecking order. A day has just so many hours, so the task is to increase the output to time ratio. This neatly meshes with the RPT process that quantifies the ranking of journal publications, teaching evaluations, and the committee work and/or community engagement undertaken. This makes it easier to reward (or punish) professors as needed.

Unfortunately, this focus on productivity carries over to the personal sphere, where the hurried life continues and checklists abound. Imbalance becomes emblematic of the ambitious professor who feels the need to follow the mantra: "Get through with one's 'home life' as quickly as possible because there is 'serious' work to be done." Those who believe that the professor leaves campus at the end of the day without books and papers in hand are simply delusional.

The submission categories 'Articles' and 'Reflections' are peer reviewed. The other types of submissions are reviewed solely by the editorial board. See www.hogreutbildning.se

(C)2018 Rory J. Conces. This is an Open Access article distributed under the terms of the Creative Commons Attribution-NonCommercial 4.0 International License (https://creativecommons.org/licenses/by-nc/4.0/), allowing third parties to share their work (copy, distribute, transmit) and to adapt it, under the condition that the authors are given credit, that the work is not used for commercial purposes, and that in the event of reuse or distribution, the terms of this license are made clear.

Citation: Rory J. Conces (2018) "Review of The Slow Professor: Challenging the Culture of Speed in the Academy", Högre utbildning, 8(2), 47-50. http://dx. doi.org/10.23865/hu.v8.1293 
The adage "There is always more work to do" is one that gnaws at every professor, even though to succumb to it is ruinous to their overall well-being.

Thankfully, as intimated by Collini, the current existential condition of the professor is not absolute. Exposing the corporatization of higher education and the plight of the professor is just the beginning of the "existential threat" that is intended to re-humanize both the professor and the intellectual life of the university. The preface makes clear that the authors regard their little book as a manifesto for the insertion of slow principles into the university. A set of new mantras becomes clear: "Slow down and enjoy being a scholar and teacher!; Enjoy interaction with your colleagues, both old and new!; and Make room for a personal life!"

The introduction is a mixture of personal reflections and the results of a number of surveys and analyses that together reify the author's concerns. As the authors make clear, academic training involves assimilation into a culture of "scholarly individualism." This is especially true of those in the humanities who are not a part of anything resembling "team science," with its crowded laboratories and extensive co-authorship of publications.

Berg and Seeber do not hide the fact that the life of the academic is a privileged one. Finding positions with comparable job security, flexibility of hours, and time to be passionate about one's work is difficult. Yet today's scholars are dealing with increasing amounts of stress, something that post-graduate students should be mindful of when deciding whether to join the academy.

Stress from both the competitiveness of academic life and the misconception that professors make up a "leisured class" conducting questionable research is nothing new. What is ratcheting up the stress levels for professors these days is the corporatization of higher education. Now professors worry about justifying their positions and their programs, especially when concerns like "return on investment," "capable workforce," and "job placement" become more pronounced in the eyes of legislators, administrators, parents, and students.

As the introduction ends, the reader understands that the rest of the book will be an attempt to use the slow movement to save both the professor and the university from the effects of corporatization. The momentous turning point for the professor will be "to act with purpose, taking the time for deliberation, reflection, and dialogue, cultivating emotional and intellectual resilience...," that is, to take back agency. As for the university, an important turning point will be the renewal of "non-instrumental intellectual enquiry...this critical thinking....at the heart of the university as a public good...."

Berg and Seeber do a masterful job in packing each chapter with insights gleaned from their own personal experiences and from the writings of others. Chapter One, "Time Management and Timelessness," is the most "visceral" of the chapters.

One truth about time that encapsulates this chapter is that no matter how much "real" time the professor has each day, it is never enough. Academic work is always ongoing, due in large measure to "increasing workloads, the sped-up pace, and the instrumentalism that pervades the corporate university." Work now begins to define the corporate academic, with time management no longer making sense as "busyness" and "one-upmanship" begin to dominate as virtuous behaviors.

Another insight is the fragmentation of the academic's workday. Between teaching, class preparation and marking, meetings, advising and mentoring, dissertation committees, and professional service, a professor's week is composed of a sequence of stressful starts and stops.

Teaching and the rest can survive fragmentation, but research is different. Some professors can eke out a sentence in-between classes, but many cannot. What they need to prosper in their 
intellectual work is "timelessness," the experience of becoming so engrossed in a task or an event that one loses all sense of time.

To offset these problems, Berg and Seeber offer five recommendations. Of those, I found lessening one's workload and carving out regular periods of timelessness to be obvious truths. Unfortunately, these are the most difficult to achieve because peer pressure and the corporate culture work to thwart them. I suggest it will take much courage and perseverance to counter such forces.

Chapter Two, "Pedagogy and Pleasure," addresses slow principles in teaching. I know when I have held a good class: when I am "jacked up," and my students feel it too as they continue the discussion in the hallway. Talking about ideas is important, but successful teaching is much more. As Berg and Seeber note, "Pleasure - experienced by the instructor and the students - is the most important predictor of 'learning outcomes." The authors' expansive exploration of affective and emotional goals, as well as cognitive and informational goals, leads to further insights, including the motivation associated with "the sense of belonging" within a learning community.

Unfortunately, these pedagogical tidbits are even more difficult to achieve when teaching online, a "sort of teaching" that is becoming increasingly common. I also teach online, but I feel much more at home in the face-to-face classroom than I do "managing" students in a virtual environment. Perhaps I am unable or unwilling to implement a "pedagogy of pleasure" for my distance education students, thus failing to produce "creative, intellectually expansive, and resilient students."

Recommendations are offered under the heading of "Enjoying Teaching" and are divided into three sets regarding (I) entering class, (2) sustaining class, and (3) preparing for class. Most of these are worth taking seriously. The recommendation that resonated with me the most deals with my least favorite activity: the marking of assignments. Their advice is to think of the assignment as something that is also "useful and enjoyable for the student themselves." Perhaps more to the point, as Therese Huston notes, "students learn on the basis of what they do in your course, not on the basis of what you know."

The most onerous of the chapters is the third, "Research and Understanding." The hallmark idea of the corporatization of university research is that it is supposed to produce knowledge that is quantifiable, applied, transferable, fundable, and profitable. It is when strategic mission statements understand "excellence" as "groundbreaking research" and when priority areas are understood in terms of "productivity" and "external funding," that faculty are "nudged" to comply with the imperatives of the institution. So-called knowledge creation may place the humanities at a disadvantage, however. To offset this, the authors procure a more apt description of the contribution of the humanities: "understanding" rather than "knowledge." By making this subtle shift, as Collini notes, publication becomes "the expression of the deepened understanding which some individual has acquired, through much reading, discussion, and reflection, on a topic which has been in some sense 'known' for many generations." This is in keeping with Berg's and Seeber's central claim that slowing down research makes it less about production and more about "contemplation, connectedness, fruition, and complexity."

Berg's and Seeber's recommendations here total nine, but three stand out and are especially meaningful for PhD students. First, do not simply search online, but wander the library stacks, allowing serendipity to assert itself, and, second, do not select the "fashionable" research topic, but work on what drives your curiosity. 
The fourth chapter, "Collegiality and Community," is the shortest, due to the difficulties in dealing with human relationships. Professors rarely consider their own wellness, which includes the interpersonal. The idea that we need support from colleagues seems antithetical to the solitary scholar. No wonder faculty offices are rarely occupied, often to the dismay of students. They are more like malls, places that one goes to only sporadically and only for short periods. Even so, collegiality and conviviality are an important part of anyone's psychological well-being.

At this juncture, Berg and Seeber offer no recommendations, but only less than rousing "points of reflection," including not making all department events mandatory, venting one's frustration, and willingness to take risks in being candid with one's colleagues. The final chapter is the weakest of the lot.

This leads into a very short conclusion, a reflection of how The Slow Professor is itself an example of a slow collaboration between Berg and Seeber. It is the product of conversation, the centerpiece of their method. Reducing shame and building trust gave them the wherewithal to push forward with this project. In the end, they were able to "think together" and resist corporatism just a bit.

The Slow Professor stands as a dedicated attempt to revive a much-needed vision of the professoriate and the university. It is a virtue of Berg's and Seeber's book that it aims to cover the diagnosis and treatment of what ails the academy in so few pages. However, its discussions of the mayhem that the corporate model has wreaked on both professor and university are integrated with recommendations that only make sense at the personal and interpersonal levels. When it comes to ways of bringing about institutional change, the book falls flat. Until such changes begin to take hold, we are all on our own.

Rory J. Conces

Associate Professor of Philosophy

Department of Philosophy

University of Nebraska at Omaha USA

Email: rconces@unomaha.edu 